\title{
Patrizia Violi
}

\author{
Università di Bologna
}

\section{How our Bodies Become Us: Embodiment,}

\author{
Semiosis and Intersubjectivity
}

\begin{abstract}
In recent years, the body and the related notion of embodiment have become pervasive objects of inquiry in numerous disciplines, ranging from cognitive science to philosophy, linguistics, semiotics, cultural anthropology, and so on. This article aims to investigate more closely the characteristics of the notion of 'body' presupposed by these different theories, which often naturalize the body by taking it as a non-gendered, pre-discursive phenomenon, and thus hiding the concrete reality of the many different bodies we all as persons possess, with all their specific social, cultural, and discursive determinations. The body is not an isolated entity, but the result of a complex set of interactions with the environment and with others, where intersubjectivity plays a crucial role. Much research over the last few years has focused on the ways in which the body has inscribed in itself a predisposition to intersubjectivity: this article discusses another, complementary, question: the way in which intersubjectivity itself shapes bodies. Here the body is seen as the result of a process that takes place in a sociocultural environment and in intimate interaction with others, rather than the starting point for a process that, beginning from the single organism, expands and opens up towards a wider relational world. In this approach, intersubjectivity becomes a semiotic dimension of the social co-construction and sharing of meaning. All forms of intersubjectivity imply, and at the same time produce, a work of continual interpretation and reinterpretation which lies at the very basis of the peircean concept of semiosis. Finally, to exemplify how intersubjectivity, semiosis, and embodiment intimately intertwine with one another, one particular field of investigation is considered: the very the first stages of human development, where it is shown how the body becomes a semiotic entity: something much more than - and very different from - a purely natural organism.
\end{abstract}

Keywords: Embodiment, semiotics, intersubjectivity, early mother-child interaction

\section{WHY BODY IS NOT ENOUGH: THE CORPOREAL TURN AND ITS LIMITS}

During the past thirty years, the human body evolved from a marginal issue into a matter of central concern to a range of disciplines. The body - with the related notion of embodiment - has today become so pervasive in cognitive science, philosophy, linguistics, semiotics, cultural anthropology, and so on that it would not be inappropriate to describe the current situation as reflecting a corporeal turn, paralleling the linguistic turn that took place in the philosophical disciplines in the first half of last century.

A corporeal turn is certainly more than welcome. It implies a radical shift away from the mind-body dualism that has characterised the history of philosophy until quite recently: a dualism that brought with it

Address for correspondence: Dipartimento Discipline della Communicazione, Università di Bologna, Via Azzo Gardino 23, 40122 Bologna, patrizio.violi@unibo.it. 
not only a conceptual separation of the two domains, but also a severe downplaying of the role the body plays in people's cognitive and emotional lives.

Today, criticism of a gap between mind and body appears to have found a widespread following: the relevance of the body - as a basis for all forms of human functioning - is now well acknowledged, accompanied by a growing awareness of the importance of bodily phenomenology. This contemporary reappraisal has led to a widely diffused understanding of the embodied basis of human cognition: according to radical embodied cognition, thoughts, categories, and even abstract concepts are all rooted in - and depend upon - their inherent bodily origins. ${ }^{1}$

There is, however, a risk present in contemporary theories of embodiment, which, paradoxically, could be described as an 'excess of body'. If, for centuries, the body did not appear to play any significant role in the mind's functioning, today one often faces an opposite situation, where almost everything seems to be located in the body - and, indeed, only there.

What exactly does one mean when one speaks of 'the body'? The diffuse use of the singular term 'the body' is revealing: it alludes to a non-gendered, pre-discursive phenomenon, hiding the concrete reality of the many different bodies all persons possess, with all their social, cultural, and discursive determinations. The concrete and variable reality of these individual bodies is often confused with the abstract notion of bodily or corporeal schemas and the role those schemas play in perception, cognition, and action. Certainly, these are important and useful concepts; but they should never be confused with 'the body' itself - nor even immediately identified with it.

There is an obvious theoretical risk in such an identification. I would define it as the risk of hypostatizing the very notion of the body, at the same time making it an abstract and generic concept. Without contextualizing the processes that construct the body, one risks ending up by naturalizing the notion of body as something isolated and definable on its own premises - rather than a way of living in the world, acting in it, and making sense of it through one's acculturated body. In many current theories of embodiment, the body is given in a general, even universal form, independent of the cultures, habits, discourses, etc., in which it is embedded. The body becomes a naturalized concept that does not need further elaboration: it is 'naturally' given. The body is something easily accessible: objectively and physically welldefined. The body appears just to be 'there': in possession of an immediate, self-evidencing character that does not need to be explained. This is not the case. Even one's phenomenological experience of the body, which appears as something immediate and given, is the result of a complex process and of the various practices that shape one's perception of it. One could say -- to paraphrase a famous slogan of Simone de Beauvoir in reference to women - that one 'becomes a body', and that this happens in the course of a long

\footnotetext{
${ }^{1}$ On this point, see Lakoff and Johnson (1999) and the more recent Gallagher (2005). For a critical review of the concept of embodiment, see Violi (2008).
} 
process implying meaningful interactions with the environment and with other bodies: both human and nonhuman: in short, a process that implies intersubjectivity and semiosis. ${ }^{2}$

The concept of 'body', is certainly not an immediate nor self-evident one, but rather the result of the various cultural discourses that construct it. There is no such a thing as the body 'in itself', to be taken naively as a given, immediate object of inquiry. Rather, the body is a construal, shaped by each of the different disciplinary perspectives that try to describe it. The body cannot be described outside the various discursive practices that define it. If one forgets the constructed nature of the body, one risks transforming it into a kind of ontological essence. No 'hard' science is able to escape this paradox. Even if the body is described in the most sophisticated technical terms, one does not arrive at some more fundamental level of description that provides a hypothetical essential 'structure' to the body - only one more way of representing it.

The risk of reductionism is always present in any form of bodily naturalization - especially those one tends to meet in contemporary neuroscience, where all aspects of cognition and life appear to be explainable in terms of neural synapses. If, in the end, people are nothing but neurons, this still does not mean that the full complexity of their behaviour can be adequately explained by - or reduced to - neurons, even if they are mirror neurons.

There is one more grave risk in the way embodiment is generally taken, which is particularly relevant for the present discussion. Most theories that are focused on 'the body' take the body as an isolated entity: something that can be accounted for on its own, without consideration of what is around it; where this 'around' is understood as the environment and the relationships each and every body enters into with others. If one of the critical aspects of classical cognitivism could be seen in its isolated mind-style stance, ${ }^{3}$ a risk of embodiment theories is the construction of an analogous isolated body, which becomes the source of meaning and the basic structural matrix of all semiotic processes.

I will give two examples of the way in which isolated body theories have developed in two research domains: cognitive linguistics and semiotics.

In cognitive linguistics, all cognitive abilities - up to abstract concepts - are embodied: i.e., grounded in perception, 'motricity', and bodily schemata, then extended to other domains through massive metaphoric extensions. ${ }^{4}$ In this way, the body is taken as the origin and primary source of meaning construction: prior to and independent of any form of social or cultural construction of sense.

The problem with such a position is the unquestioned nature of 'the body', which is reduced to a universal abstract schematic structure, while ignoring its inherent complexity when viewed, for example,

\footnotetext{
${ }^{2}$ With 'semiosis' I am referring here to the idea of the continuous and potentially endless process of interpretation of signs and consequent attribution of meaning to our experience of the world, following the tradition of the philosopher Charles Sanders Peirce.

${ }^{3}$ Many - apparently insolvable - philosophical problems depend on the the isolated mind position: first of all, the well-known problem of other minds. Other minds constitute a problem only if one considers minds as monadic, selfdefined entities: isolated subjects that encounter other isolated subjects. If one sees oneself as inhabiting a world that is necessarily shared with others, the problem turns out to be illusory (see Zahavi 2001). For an alternative to classical theory of mind or theory theory based on intersubjectivity, see (Gallagher 2005).

${ }^{4}$ See in particular (Lakoff 1987).
} 
from a phenomenological point of view, which in its turn is affected by the surrounding cultural environment with all its diversity. Indeed, what Lakoff and similar approaches take into account is mainly the system of spatial bodily orientations, statically defined: e.g., vertical positioning, lateral structure, sensorimotor interactions with the environment, and so on. I am not denying that embodied schematic structures are intertwined in interesting ways with content schemata; but this is not enough: in order to understand the full nature of embodiment, one should move towards a more dynamic vision, taking into account the interaction of the body with its environment and the co-constructed nature of meaning - which, in turn, open up cultural meaning variations.

The semiotic approach to the body appears likewise unable to escape this kind of reductive reading. Despite the many interesting and important results he has managed to achieve, Jacques Fontanille (2004) among contemporary semioticians, the one who probably has worked the most on the relevance and role of the body in the semiotic domain - nevertheless seems subject to the same criticism as I offered of cognitive linguistics, even though his analysis takes a different, more articulated, perspective. He describes the various instances in which the body can be analyzed - distinguishing, in a phenomenological vein, between the chair (flesh) and the corps propre: showing their different semiotic functions; but he fails to take into account the role of intersubjectivity and thus conceives of the body as if it were an entity in itself, independent of its interactions with other bodies. His analysis misses the relevant shaping and transformative function that interactions with others have on one's flesh, one's body.

I would like to make this picture more complex: first of all, by bringing together embodiment and intersubjectivity, to show that it is precisely through intersubjectivity that one constructs one's sense of one's body; second, by claiming that this follows because intersubjectivity is primarily a device to produce or construct meaning. It is through intersubjective co-production of meaning that bodies adjust to each other and to the environment, becoming what they are.

\section{THE CONSTITUTIVE DIMENSION OF INTERSUBJECTIVITY}

Bodies are always plural entities: always situated in a cultural environment where they interact with other bodies, always immersed in a complex world of intersubjective and inter-objective relationships that must be continuously interpreted, and out of which people must make sense. The body does not exist in isolation from other bodies: one always, and only, has a body that interacts with other bodies: bodies that encounter one another or do battle with one another. If one ignores this being-together-with bodily dimension, one will never understand exactly what 'the body' is. Subjectivity is where one must start in order to understand the body, and not the other way around. This is not obvious in many contemporary discussions.

The idea that embodiment must be intertwined with intersubjectivity, is shared by scholars from a number of disciplines, ranging from philosophy to psychology to neuroscience, with the latter's recent progress on the neurological correlates of social cognition: notably, the discovery of mirror neurons.

There are, however, important differences in the way one should interpret the two concepts in focus here: intersubjectivity and embodiment. Often, in the debates over embodied social cognition, the focus is on 
how intersubjectivity is shaped by the architecture of human bodies. Studies on mirror neurons and neonate facial imitation exemplify this approach, emphasizing the built-in, genetic, even neural predisposition of the body toward social interaction. What all the studies show is that intersubjectivity is inscribed in one's very body: a challenging and even revolutionary truth, especially if one is used to the solipsistic approach of isolated mind.

However important this approach may be, I would rather take a different one - not necessarily opposed but hopefully complementary - investigating the other side of the question. Rather than asking about the way intersubjectivity is shaped by bodies, I want to look at the way in which it shapes bodies.

Contrary to intuition, the body is not the starting point for a process that, beginning from the single organism, expands and opens up towards a relational world; quite the opposite: the body is the result of a process that takes place in the environment and in interaction with others. One begins the journey to meet the body in the relational character of one's world and the inherently semiotic nature of one's experience of it.

The primacy of relations has always been a fundamental issue for semiotic theory, manifest in both C.S. Peirce's Logic of Relatives and in Louis Hjelmslev's structuralism. In both cases, reciprocal relationships both define and allow the identification of individual entities or elements - not the other way round. From its beginnings, semiotics has always claimed priority for relationship, over individual elements.

If this is true, one should apply the principle to study of the body, starting from the network of relations that establish its existence - rather than focus exclusively on embodiment and cognition. It is not enough to state that body and mind are one and the same, or that all mental processes are embodied, if one fails to see the ways bodies are reciprocally constituted within an intersubjectively defined world. However, to do that, one must first understand better semiosis' role in the process, as it interrelates with intersubjectivity.

By intersubjectivity, I mean more than just intercorporality. Although certainly rooted in embodied interactions, intersubjectivity implies a semiotic dimension of meaning's social co-construction. From the beginning of life, one is constantly engaged in sense-making activity - however rudimentary - resulting in endless survival-facilitating interpretation of the world in which one is immersed. All forms of intersubjectivity imply and at the same time produce a work of continual interpretation and reinterpretation, which lies at the basis of the peircean concept of semiosis. This semiotic character of intersubjectivity and embodiment is their fundamental essence.

If intersubjectivity's relevance is widely recognized today, less attention is paid to its inherently semiotic character as the primary place for meaning construction. This inattentiveness can probably be traced back to a still-pervasive conception of meaning as mental representations. To understand the intersubjective construction of meaning fully, one must move away from a mental/representational approach to a different view of cognition where meaning is distributed among actors and the mind is no longer the internal, individual apparatus where cognitive processes take place. It is rather replaced by an extended, "external" mind. This is not the place to discuss such complex matters. Suffice to say that such an alternative view of 
meaning and of social cognition is becoming popular in cognitive circles. Note that, from a semiotic perspective, it is not that new: it goes back to the Peirce's cognitive semiotics. ${ }^{5}$

I wish to exemplify how intersubjectivity, semiosis, and embodiment intertwine by looking at a particular field of investigation: the first stages of human development. I am not going to present any new research; rather, I will discuss well-known examples from the literature on developmental psychology, using established data as examples to illustrate and support the argument I have developed so far: showing, through concrete empirical evidence, how embodiment is constructed through intersubjective exchanges with their intrinsically semiotic nature.

\section{PRIMARY SEMIOSIS AND THE RELATIONAL FRAME}

If any field of inquiry exists where the body is taken as an inescapable starting point, it is the study of the beginnings of human life: a developmental period I shall refer to as primary embodiment. An infant is, essentially, a body, with sensations, hunger, pain, feelings of satisfaction, and movements: a body that feels and reacts. The body is where affect first takes place, the vehicle within which subjectivity develops. Freud (1923) was well aware of this basic bodily constitution when he referred to this first ego as body ego.

According to Freudian (1914) and other classical psychoanalysis (Mahler 1968, 1975), the first stages of infant life are characterized by primary narcissism: a state of happy unity with the mother with whom the newborn infant is symbiotically united, having no experienced sense of differentiation.

A different position has emerged in recent decades within the broad current of infant research, out of close collaboration between psychologists, psychoanalysts, psychiatrists, and pediatricians. ${ }^{6}$ The results paint a very different picture of the first phases of newborn infants' lives. Infants are not undifferentiated entities fused with their mothers; on the contrary, from the beginning of their lives and perhaps even before, in the womb, they are capable of discriminating between stimuli. They can distinguish the sound of their mother's voice or the smell of her milk from that of other women. Perhaps most important for the present discussion is the high level of interaction newborns exhibit with adults and the inherent complexity of their behavioural responses to the environment.

If newborns are primarily bodies, they are always intersubjective bodies. Today, the role of intersubjectivity - even in the phase in which infant life consists mainly of a body and its functions (i.e., before language and fully developed consciousness) - is widely recognized. (See e.g. Trevarthen and Aitken's (2001) comprehensive review.)

\footnotetext{
${ }^{5}$ See (Fusaroli, Granelli \& Paolucci 2011) - in particular Paolucci's article The 'external mind' -- for discussion of contemporary debate over distributed cognition from a semiotic point of view.

${ }^{6}$ A full account of this research is beyond the scope of this paper. A few of the most seminal works include (Stern 1985, Neisser 1993, Tronick 1982,Tronick et al. 1978, Trevarthen 1993). For recent references extending to the period of first language acquisition see (Bloom 2005; Gelman 2007; Goswami 2007, 2008; Nelson 1996; Schneider \& Bullock 2009).
} 
The first evidence appears as soon as a child is born, as shown by experiments on neonate imitation. ${ }^{7}$ Newborns' imitation behaviours display not only an established proprioceptive sense of one's own body and a distinction between self and non-self: quite different from the unity Freud presupposes; but also a recognition that another person is of the same species. ${ }^{8}$

Born only a few hours before, neonates cannot have any previous experience of facial expressions nor any training to act in an imitative way. They cannot possess any interiorized schema for imitative movements. One must probably assume a built-in, genetic predisposition towards interaction, probably as, in evolutionary terms, a survival device. ${ }^{9}$ Intersubjectivity appears inscribed into their very bodies - perhaps at the neural level, if one is to believe in the proposed function of mirror neurons. Neonate imitation shows that the "sense of other is already implicit, at least in primitive way, in the behaviour of the newborn" (Gallagher 2005: 225).

What is interesting for purposes of my argument is the constructive process that follows the first imitative moves. Infant behaviours always elicit a response from the parents. If this response is positive, it reinforces a tendency towards subsequent repetitions. If the first imitative behaviour is built in - possibly determined by mirror neurons (Gallagher 2005: 77) - then what follows depends on a complex system of intersubjective, environmental reinforcement. Prolonged positive feedback reinforces certain behaviours, weakens others, and thereby determines a tendency to certain actions: precisely what Peirce described as the creation of a habit, which, in its turn, is the basis of belief. What is important to emphasize is how intersubjective responses determine the forms that neonates' innate predispositions take.

Imitative behaviour can be reinforced or repressed. What can be taken at the beginning as pure innate predisposition to intersubjectivity develops into a complex semiotic response to an ecological, intersubjective environment. One could object to talk of semiosis and semiotic behaviour at such an early stage. However, if - following Eco (1975) - one takes semiosis as any response to the environment that is not causal and constrained by a stimulus response pattern, implying a possibility of freedom and variation, one can easily recognize the beginnings of a semiotic life. Eco called this space of freedom Space C. However minimal it might be, a Space C's existence between stimulus and response testifies to the non-deterministic character of the response and, therefore, the presence of semiotic mediation. It is precisely a behaviour's mediated nature that allows us to define it as semiotic: i.e., not reducible to causal response to a stimulus. If a neonate's first imitation may well be no more than 'natural', repetition of imitative behaviour, due to intersubjective reinforcement from adults, is already semiotic, because it is mediated by the adults' response: i.e., the adult is the interpretant (in Peirce's sense) of the infant's behaviour. Even more striking evidence of how semiotic intersubjectivity affects infants' bodily responses - exhibiting, at the same time, complex construction of

\footnotetext{
${ }^{7}$ Cf. (Meltzoff \& Moore 1977, Meltzoff 1989). These experiments show how - only a few hours after birth - neonates can reproduce facial gestures performed by an adult. Neonates seem sensitive to all movements involving the lower part of the face: e.g., protrusion of the tongue or opening of the mouth. As soon as they see an adult doing these things, they happily reproduce the movements.

${ }^{8}$ See (Gallagher and Meltzoff 1996).

${ }^{9}$ For discussion, see (Gallagher 2005).
} 
social meaning - can be found in Tronick's famous 'still face' experiment (Tronick et al. 1978), since repeated many times at ever earlier ages. ${ }^{10}$

Clearly, infant behaviour is much more elaborate than the simple imitative reactions shown in Meltzoff's experiments on facial gestures, in which infants do not imitate anything: they interpret the mother's behaviour and interact with her in meaningful ways, exhibiting a high variety of responses that lie outside any deterministic schema. The ways infants sense their bodies and produce meaning in the interaction with their mother are closely interconnected. The intersubjective relation is the frame that makes possible both construction of meaning and more articulated perception of one's own body. The child's phenomenological body (Merleau-Ponty's corps propre) is affected by - and results from - the structuring of the intersubjective relation, which is where meaning and semiosis first take place.

Paralleling developmental psychologists' notion of primary intersubjectivity (Trevarthen 1979) is what one might call primary semiosis: i.e., the sum total of these phenomena. Primary semiosis covers all cases where meaning is co-constructed by actors in praesentia, where one does not yet have clear evidence of semiotic substitution (something standing for something else) as is the case in fully developed semiosis.

Early mother/child interactions are characterized by complex, embodied synchronization of both participants. The infants' body movements are constantly adjusted - or tuned - to those of the mother. ${ }^{11}$ According to Trevarthen and Aitken (2001: 5), 'as early as 2 months, infants and mothers, while they were looking at and listening to each other, were mutually regulating one another's interests and feelings in intricate, rhythmic patterns, exchanging multimodal signals and imitations of vocal, facial, and gestural expression'. Mutually regulated interchanges exhibit turns of displaying and attending that parallel verbal conversations and have hence been called proto-conversations (Bateson 1979).

With little doubt, communicative exchange is part of these interactions. Where there is communication, there is meaning, however simplified; and, therefore, a form of (primary or proto-) semiosis. The coconstructed meaning of early interaction is anything but rudimentary. Its primary nature consists not of simplified form, but rather non-systematic and non-codified character. It is not cognitive, conceptual content but emotionally affective meaning that is completely embodied: inscribed in rhythms, movements, intonations, gazes, smiles, and so on. ${ }^{12}$ Not all meaning is symbolic meaning, encoded in words and structured in sentences.

The transition from primary to secondary - more fully developed - semiosis is complex, implying several passages that one can imagine as a progressive 'thickening' of meaning more than radical shift.

\footnotetext{
${ }^{10}$ The experiment involves alteration of the usual behaviour of the mother as she plays with her baby. During an otherwise normal interaction where the mother plays with the infant sitting on her lap, the mother is asked to stop all movement and facial expression and remain still for two minutes. Infants respond in incredibly complex ways to the unexpected change of behaviour, even before the age of two or three months. They immediately and clearly recognize a strong discontinuity in the mother's behaviour. Their first reaction is amazement and a certain annoyance, after which almost all infants try to re-animate their mother: touching her face, smiling, moving closer to her. When these attempts fail, infants try different strategies: some start crying; others withdraw; others start playing with their body, touching their fingers and faces as if to compensate for the mothers' distracting behaviour.

${ }^{11}$ Stern (1985) describes such interactions as interactive dance.

${ }^{12}$ For discussion of the role of emotion and affect in cognition see for example Damasio $(1994,1999,2003)$, Frijda (1986), LeDoux (1996).
} 
Again: the acquisition of semiotic competence is always done within - and determined by - an intersubjective frame, where the body is both the natural ground and the constructed outcome. In what follows, I consider some paradigmatic examples. 


\section{FROM BODY TO SIGNS}

In her first months of life, an infant has only limited ways to interact meaningfully with her environment: to voice her feelings and otherwise try to express herself. She can only use her body and the restricted range of movements it can perform: a body that is, at one and the same time, an organon that feels and perceives the world and her only way to articulate meaning. How can one describe meaning at such basic levels? How does it develop out of the body?

To develop some form of meaning - however rudimentary - one must have a semiotic function: i.e., an expression and a content that are interconnected but distinct. This is the semiotic mediation I referred to earlier, whereby something stands for something else.

The earliest, primary forms of semiotic function cannot but be profoundly embodied. Infants have only their own bodies as instruments of signification. Elements of the sensible plane - body movements, gestures, rhythms, and so on - must be made pertinent and indexically connected to elements on a different plane, able to act as content. In this way, somatic elements become vehicles for semantic content.

This is a particular case of semiotic translation between bodily perceptions and communicable expressions: more precisely, inter-semiotic translation. The problem is not that different from the sommelier $^{13}$ who must translate gustatory stimuli into language. Such translations imply a shift from a proprioceptive realm of internal sensations belonging to one's individual phenomenology - as such, they are incommunicable - to an intersubjective realm of cultural values. What the sommelier does is no more than translate from internal, somatic sensation into a cultural semantic system. To do that, she must 'semiotize' her sensible experience, which implies several steps. First of all, she must decompose what is perceived as a unitary gustatory experience into distinct components. Then, she must isolate some of these sensations and make them pertinent. Finally, she needs to associate these pertinent elements with some 'macro' category at the level of content - e.g., structured vs. unstructured wine - constructing/producing a structural coupling between perceptive sensations and semantic content categories.

Something similar happens in the case of the infant, who is in a somehow similar situation to the sommelier. To communicate, she must indexically translate internal sensations - e.g., feelings of pain or hunger - by way of different forms of embodied semiosis.

Empirical evidence suggests that this is precisely what happens in the first months of life. In my own direct observation of one infant ${ }^{14}$, I noted the following sequence. The boy is three months old and has an unpleasant skin irritation around the groin, which is very red. He cries despairingly while lying on the table having his diaper changed. However, when his mother touches the skin where it hurts, the boy stops crying and turns his head toward her.

How should one interpret such behaviour? Certainly, the mere touch of the mother's hand has not alleviated the discomfort. The boy does not stop crying because the pain has ceased. One can hypothesize

\footnotetext{
${ }^{13}$ For discussion see (Paolucci 2010), in particular Section 2.6.

${ }^{14} \mathrm{My}$ observation was conducted along the lines of the infant observation methodology described by Esther Bick (1964), used nowadays in most psychoanalytic training programs: for two years, starting at birth, the infant is observed once a week for one hour, always at the same time - thereby maintaining a constant observational setting.
} 
that the boy - while continuing to feel discomfort - senses that his mother had identified the reason for his discomfort by touching the sore spot. One need not postulate any complex inferential reasoning such as if mummy touched me where it hurts, then she will take care of it'. The infant need only feel that his pain has been perceived and understood: he is neither abandoned nor alone. As Gallagher writes, 'this kind of perception-based understanding is a form of "body-reading" rather than mind-reading. In seeing the action and expressive movements of the other person, one already sees their meaning: no inference to a hidden set of mental states (beliefs, desires, etc.) is necessary' (Gallagher 2005: 227).

From my point of view, what is interesting is the way the boy is able to modulate and use his own crying. Although, originally, his crying might not have a expressive communicative component - being just a natural response to a painful stimulus - its immediate cessation implies a communicative intent: he is using his crying as a plane of expression to indicate something else. In so doing, he constructs his own, 'micro-' semiotic system. A simple system of oppositions on the expressive plane - presence vs. absence of crying relates to equally basic differences at the level of content. However minimal the system might be, one sees already a semiotic structuring of body signals. While these semiotic beginnings are deeply embodied taking place, literally, within the body itself - they could not have developed outside the specific relational context of interaction with the mother. This intersubjective framing stimulates his first attempt to make meaning and so communicate. If the mother were not present, the boy would probably not stop crying. If he did stop crying, it clearly would not have the same meaning.

Several conclusions can be drawn about the reciprocal interdependence of body, meaning, and intersubjectivity. First is the logical priority of the intersubjective environment: the body can be a vehicle for meaning only if it interacts with a significant other - only within the intersubjective frame of a self/other relationship. Second is the reciprocal co-construction of body and meaning. Meaning is embodied, because the body is the first ground of a semiotic function acting as the plane of expression. The body becomes, in its turn, a semiotic entity: something more than - and different from - a purely natural organism.

Tuning - as studied by Stern (1985) - is another instance of embodied behaviour taking form within an intersubjective framework and affecting bodily construction. I have already shown that - from birth mother/child interactions are characterized by synchronization: imitative reciprocal adjustment of one to the other. Together with their adult caretakers, young children create sequences of interactions that represent a first form of social dialogue. During the first six months or so, these interactions take the form of repetitions: the mother uses exactly the same expressive modality as the infant. If the infant vocalizes, the mother vocalizes, too. If the infant grimaces, the mother grimaces. These repetitions always occur as sequences of micro-variations that make these 'dialogues' far more than boring iterations.

From the seventh or eighth month, it is possible to notice a change in these dialogues: what Stern calls a tuning of affect. The main difference between imitation and tuning is that tuning involves semiotic transmodal conversion: some expressive modality is translated into another form. ${ }^{15}$ One no longer has

\footnotetext{
${ }^{15}$ Here are two examples taken from Stern. (1) A nine-month-old girl tries to grab a toy; when she succeeds, she forcefully exclaims 'aaah!' while looking at the mother. The mother returns the gaze and makes a movement with the
} 
simple imitation but inter-semiotic translation (Jakobson 1959), where the object of correspondence is not so much the behaviour itself but some aspect of it that has to do with the mood. The correspondence occurs among expressions of internal states that may differ in form or modality but are somehow interchangeable as manifestations of the same internal state.

To some extent, tuning shifts the focus from external behaviour to the core of semantic meaning behind it. It shifts the focus from behaviour to what the behaviour means; in this, it reveals its essentially semiotic nature. This is a particular form of semiotic translation, converting verbal expressions into motor ones or vice $v e r s a$, with the body as the operator. During translation, the channel changes; while other features - such as rhythm, intensity, duration, intonation, or emotional tone of movements and vocalizations - remain unchanged. The infants' pleasure reactions, gaze, and ability to coordinate with the mother show that the infants have not missed the translational nature of the tuning. They are able to grasp that the same content or quality can be expressed in many different ways, using different modalities, resulting in many comparable expressions. $^{16}$

Tuning is different from and much more complex than simple imitation. It also differs considerably from contagion: a phenomenon that has received attention recently in semiotics. ${ }^{17}$ A case of contagion is the simultaneous initiation of crying by infants, where one witnesses diffuse stimulus propagation, not a transformative process of translation. By contrast, in tuning one finds the beginnings of a semiotic competence in precisely the capacity of the infant to distinguish an invariant core of meaning underlying variable forms, along with a principle of substitution among and between those forms. Here again one sees how the subjective experience of being a body is constructed and shaped by an intersubjective environment through semiotic mediation. This is even more evident when one considers the emergence of a more explicit, more complete infant semiotic competence.

\section{INTERSUBJECTIVITY AND EMBODIED SEMIOSIS}

The phenomena considered so far can be described as primary or implicit forms of semiosis. At some stage in development - around nine months - one witnesses the emergence of explicit semiotic competence, in which one can hypothesize internalization of the semiotic function. This developmental shift is particularly relevant for my purposes: it allows one to better understand the intertwining of body, intersubjectivity, and semiotic functioning.

\footnotetext{
upper part of her body, of exactly the same duration as the child's 'aaah!', with the same level of intensity and playful excitement. (2) A boy of about nine months slams a toy on the ground in a steady rhythmic movement, with great intensity and pleasure. The mother inserts herself into the rhythm with an expression like 'kaaa-bum', aligning the 'bum' with the slam and the 'kaaa' (in a rising intonation) with the child raising his arm.

${ }^{16}$ The infant perceives the emotional states of the other through bodily movements, expressions, rhythms, and intonations. All are embodied forms of understanding and not mental states.

${ }^{17}$ Cf. (Landowski 2004).
} 
As is well known, the period between seven and nine months is crucial in infant development. Around nine months, one sees an evolutionary leap forward in the acquisition of new skills, having mainly to do with an increased ability for intersubjective exchange. ${ }^{18}$

One of the most revealing signs of this transition and the complexity of the requisite sharing mechanism is the pointing finger phenomenon: the natural evolution of a common interaction situation. Until seven to nine months, every time the mother or any other adult points to indicate a third person or object, the infant never follows the direction of the finger, but simply watches the finger - sometimes trying to grab it. Then something extremely interesting happens: the infant stops looking at the finger and starts looking in the direction in which the finger points. This is evidence of the emergence of a specifically semiotic competence. The finger is no longer merely a finger; it is now interpreted as a semiotic device: a true sign that stands in some sense or other for something else, according to one of the most well-known definitions of 'sign'. What one has is, more precisely, an ostensive sign or an index as the first form of semiotic function and the first element of what can appropriately be considered explicit or secondary semiosis.

Operating in reference to something other than itself, the sign broadens the horizons of the dyadic mother/infant relationship by opening up a third element. The indexical function connects to the world outside the dyad, helping the infant escape her 'binary' relationship with her mother and move towards a more complex, more dynamic 'tripartite' relationship with the external world.

The case of the pointing finger involves much more than acquisition of a purely cognitive semiotic competence to refer. If one continues observing what happens following the mother's indexical gesture, one sees that the infant, having looked in the direction in which her mother has pointed, turns her gaze back to her mother, waiting for a sign of confirmation. The infant watches her mother's eyes to verify that the direction of gaze and identification of referent are as intended. Only if the mother confirms by e.g. smiling and looking in the same direction does the infant turn again to look where she is pointing - at the same time possibly initiating an action like trying to grab the object pointed to or stretching her arms towards it.

One can draw some conclusions. First, emergence of explicit semiotic competence - where the infant shows clear evidence of a capacity to understand and control the mechanism of semiotic reference - always takes place through embodied action within a relational frame that establishes and regulates the competence. The capacity to interpret sign functions correctly arises not in an abstract mental space separate from the environment but always and only within a delimited intersubjective space, as a form of embodied practice.

The act of reference, along with its associated competence, is a process that can only be understood from the perspective of a relational, intersubjective framework incorporating those practices carried out

\footnotetext{
${ }^{18}$ There are three key areas of increased sharing: attention, intentions, and affect. The basic intersubjectivity present in infants' behaviour from the first hours of life can now be specified along three lines: inter-attentionality, interintentionality, and inter-affectivity. These are not completely separable: attention and intention are often linked. Sharing attention almost always involves an intention to participate in some activity with others. Meanwhile, an infant's contact with others always implies an affective dimension: unless pathological states intervene, it is almost impossible to interact without sharing emotional states. In the case of early interactions, emotions operate as an instrument for orientation and a guide to action.
} 
within the framework. One learns to relate successfully by performing actions together with another human being.

This conception of referentiality is very different from the traditional one of analytical philosophy and logic. Far from being a purely cognitive ability to achieve an appropriate mapping between signs and external reality, referential competence develops from embodied practices within an intersubjective field.

The relevance of action to meaning making has recently become much more widely acknowledged. In particular, the theory of enaction or action in perception ${ }^{19}$ has pointed out the body's central role in human consciousness and cognition. That said, the importance of the intersubjective and inherently semiotic frame, intimately intertwined with the body, does not seem to play a major role in enactive thought, remaining very much in the background. By contrast, on the perspective I am proposing, action and embodiment cannot be understood fully without taking into account the relational dimension as the first, basic environment in which meaning takes form. From a semiotic perspective, action always implies a complex relational framework, even in the case of a single action performed by a single agent. Every action involves a goal or target, somebody or something affected by the action, and so on.

The intersubjective framing of referential activity implies continuous adaptation and adjustment to what is going on. Reference is not a pre-fixed correspondence relation but a negotiated activity, progressively tuned by mother and infant to the exigencies of the situation. The infant learns to connect signs to things in a pragmatically negotiated 'doing together' governed by the infant's communicative relationship with her mother. In this way, the communicative dimension, which is essentially relational, precedes and makes possible the forms of signification in play - not the reverse.

No longer is reference a matter of the proper functioning of a single ostensive sign. Rather, it must be understood within a complex narrative scheme endowed with actantial roles the infant is already to some extent able to recognize. The mother is a kind of natural 'addresser', fixing the values and goals at stake. She plays a crucial role at the level of what in narrative semiotic terms is called sanction: the positive or negative recognition of what has been accomplished. ${ }^{20}$ As I have shown, it is the mother who, with her gaze and attitude, confirms or denies the success of the infant's attempt to identify some given reference. The acquisition and development of semiotic competence in its earliest stages is both embodied in action and governed by the child's relationship with her mother within a framework that is at one and the same time narrative and communicative.

In the case of the pointing finger, what happens is a complex triangulation between three semiotically distinct players or actants: the infant's body, the mother, and the 'outside' world. The relationship between the three sides of this triangle is complex and circular: it would be far too simplistic to consider only one side of the triangle, such as the one where the mother operates as control actant and regulator of the infant's relationship with the world; even though it is the mother who drives the infant's semiotic functioning and the mother/infant relationship that regulates the infant's world. At the same time, the relationship that the infant

\footnotetext{
${ }^{19}$ See (Noë 2004, 2009).

${ }^{20}$ I refer here to narrative theory as developed in the semiotic framework of (Greimas and Courtes 1979).
} 
establishes with the world has a feedback effect on the infant's relationship with her mother, in a circular relation that involves all sides of the triangle. The infant not only uses the adult to verify her referential procedures and anchoring to reality; she uses the referential procedures to verify her relationship with her mother. A referential act that is carried out 'correctly' - i.e., following the mother's intentions and successfully identifying what the mother intended to be identified -- serves also to confirm and reinforce the infant's relationship with her mother. The case of the pointing finger shows not only the infant's ability to share attention, but also its capacity to understand the mother's intentions and to adapt. What is at stake is far more than the acquisition of a ostensive semiotic competency; what is at stake is a complex strategy that must be read in terms of embodied intersubjective intentionality.

Narrative semiotics defines this and similar sequences as forms of manipulation, where by 'manipulation' one is meant to understand 'any action of a man on other men in order to make them perform a given program' (Greimas and Courtes 1979: 220): i.e., an attempt to make the other do something within a particular reciprocal dimension, at different levels of influence. The mother's manipulation of the infant is the more obvious one, being directed at recognition of the ostensive act. What is at stake for the infant is, first of all, the capacity to correctly interpret the mother's intentions. Those intentions fulfilled, the infant can seek to obtain a positive sanction, thereby manipulating the mother. Meeting the mother's expectations gives the infant precisely the approval necessary to satisfy her needs and desires. The triangulation with the pointing finger goes beyond the mother/infant dyad that so strongly characterizes the infant's first experiences and interactions. The intersubjectivity becomes more complex, because the reality external to the mother/infant dyad comes to play a mediating or actantial role in the relationship. What one has here is a system with three mutually interacting positions: the mother; the infant; and the world of reference, composed of other people or things. Semiotics characterizes such situations in terms of inter-actantial relations, where inanimate objects may also play an actantial role, entering into relationships with other actants and assuming various roles.

Developmental psychologists refer to the same type of relational context as secondary intersubjectivity, ${ }^{21}$ by which they mean an infant/mother interaction that is mediated by an object. For Hobson (2002: 62), 'the defining feature of secondary intersubjectivity is that an object or event can become a focus between people. Objects and events can be communicated about, the infant's interactions with another person begin to have reference to the things that surround them'.

Independently of which terminology one adopts - that of secondary intersubjectivity or semiotic interactantiality - one arrives at a situation that is no longer dyadic but triadic. This seems to be a necessary condition for emergence of what I have termed explicit semiotic competency, which one can usefully distinguish from the more basic forms of embodied meaning described in the preceding paragraph. Once again, only in the niche of an intersubjective semiotic environment can complete mastery of bodily functioning develop.

\footnotetext{
${ }^{21}$ See e.g. (Trevarthen 1993, 1998; Trevarthen \& Hubley 1978).
} 
If the case of the pointing finger shows how early semiosis depends on an intersubjective context in which attention and intention are shared, one must not forget that intersubjectivity is always - perhaps primarily - the sharing of affective states, as the tuning phenomenon demonstrates. This is an important point for my argument. Affect is a central component of embodiment, perceived in the first instance both in and through the body. If affect is also shaped by intersubjectivity, this means that the body itself, with all its reactions and perceptions, is affected by intersubjective relationships.

Emotional competence - the ability to take the 'right' emotional attitude towards events and situations, especially new and unexpected ones - is a core component of one's ability to make sense of experience. The visual cliff and frightening object experiments are particularly significant here. ${ }^{22}$ These and similar experiments demonstrate the central role of the intersubjective relationship to the development of infants' emotional attitudes: in particular, attribution of emotional value to objects and situations. Emotional value is, perhaps, the deepest level of meaning one can achieve. It shapes one's relationship with the world, establishing the value to be attributed to experiences and the attitudes to be adopted for driving actions.

Emotional attitudes in infants - and the bodily behaviours determined by them - clearly result from adults' responses to the infants. The adults' responses act as a kind of emotional regulator. They can be seen as interpretants in Peirce's sense: more developed signs that interpret infants' first reactions, influencing subsequent actions. The situation is similar in many respects to neonates' facial imitation, analyzed earlier. The creation of habits - which are, at the same time, tendencies to action and established forms of interpreting the world - result from a complex semiotic process that does not take place in the mind, nor exclusively in the body, but develops within a distributed, intersubjective, semiotic environment.

Intersubjectivity can be seen as the basic device that, from the early stages of development, translates embodied action and experience into semiotic reality through a series of steps, from forms of tuning to more complex mediation with reality itself. Acting as a semiotic operator between the infant's embodied experience and the outside world, intersubjectivity becomes a powerful interpretant of the body: an indispensable translator that allows embodied experience to be transformed into semiotic form.

\footnotetext{
${ }^{22}$ Gibson and Walk first tested the visual cliff in 1960, to establish if sense of depth is innate or acquired. The experiment consists of putting a few-month-old infant on a table whose surface consists, at a certain point, of transparent glass, then observing its behaviour. Most infants stop when they reach the edge of the transparent glass and see the emptiness beneath them: they do not proceed. Gibson and Walk repeated the experiment with approximately nine-month-old infants with one important variation: the mothers were asked to stand on the opposite side of the table, watching their infant. When the infant stopped on the edge of the 'cliff' looking at the mother, the mother would behave in either of two manners. In one group of subjects, the mother would smile and show a calm, reassuring attitude; in the other group, the mother would appear worried or frightened. Invariably, infants in the first group, after looking at the mother several times, crossed the abyss. Those in the second group stopped, and showed signs of fear. The frightening object experiment yields similar results. A strange, unknown object that is potentially a little frightening - such as a metal object with spikes - is placed in front of an infant, in the presence of the mother. All infants around nine months look at the mother before touching the object, then regulate their behaviour according to the attitude expressed by the mother: grabbing the object if the mother smiles, retreating somewhat frightened if the mother knits her brow or shows other signs of concern.
} 


\section{REFERENCES}

Bateson, M.C. (1979). The epigenesis of conversational interaction: A personal account of research development. In Bullowa, M. (ed.), Before Speech: The Beginning of Human Communication (63-77). London: Cambridge University Press.

Bick, E. (1964). Notes on infant observation in psychoanalytic training. International Journal of Psychoanalysis, 45: 558-566.

Bloom, P. (2005). Descartes' Baby : How the Science of Child Development Explains What Makes Us Human. London: Arrow Books.

Campos, J. \& Stenberg, C. (1980). Perception of appraisal and emotion: The onset of social referencing, in Lamb, M. \& Sherrod, L. (eds.), Infant Social Cognition, Hillsdale, NJ: Erlbaum.

Damasio, A. (1994). Descartes' Error: Emotion, Reason, and the Human Brain. New York:: Putnam.

Damasio, A.(1999). The Feeling of What Happens: Body and Emotion in the Making of Consciousness. New York: Harcourt.

Damasio, A.(2003). Looking for Spinoza: Joy, Sorrow, and the Feeling Brain. New York: Harcourt.

Emde, R. \& Sorce, J. (1983), The rewards of infancy: Emotional availability and maternal referencing, in Call, J., Galenson, E. \& Tyson, R. (eds.), Frontiers of Infant Psychiatry, New York: Basic Books.

Fontanille, J. (2004). Figure del corpo, Roma: Meltemi.

Franck, R, Dirven, R., Ziemke, T. \& Bernárdez, E. (eds.) (2008). Body, Language and Mind. Volume 2: Sociocultural Situatedness. Berlin: Mouton de Gruyter.

Freud, S. (1914). On narcissism: an introduction. SE, 14: 67-102.

Freud, S. (1923). Ego and Id. SE, 19: 17-25.

Frijda, N.H. (1986). The Emotions. Cambridge: Cambridge University Press.

Fusaroli, R., Granelli T. \& Paolucci C., (eds.) (2011). Special issue of Versus - Quaderni di studi semiotici The external mind: Perspectives on mediation, distribution and situation: 112-113.

Gallagher, S. (2005). How the Body Shapes the Mind. Oxford: Oxford University Press.

Gallagher, S. \& Meltzoff, A. (1996). The earliest sense of self and others: Merleau-Ponty and recent developmental studies. Philosophical Psychology, 9: 213-36.

Gelman, S.A. (2007). The Essential Child. New York: Oxford University Press.

Gibson, E.J. \& Walk, R.D. (1960). The 'visual cliff'. Scientific American, 202: 67-71.

Goswami, U. (2007). Blackwell Handbook of Childhood Cognitive Development. Malden, MA: Wiley Interscience.

Goswami, U. (2008). Cognitive Development, The Learning Brain. New York: Psychology Press.

Greimas, A. \& Courtés, J. (1979). Sémiotique. Dictionnaire raisonné de la théorie du langage. Paris: Hachette.

Hobson, P. (2002). The Cradle of Thought. London: Macmillan.

Jakobson, R. (1959). On linguistic aspects of translation. In Brower, R.A. (ed.), On Translation (232-239). Cambridge, MA: Harvard University Press. 
Klinnert, M.D., Campos, J.J. \& Sorce, J.F. (1983). Emotions as behavior regulators: Social referencing in infancy, in Plutchik, R. \& Kellerman, H. (eds.), Emotion: Theory, Research and Experience. New York: Academic Press.

Lakoff, G. (1987). Women, Fire, and Dangerous Things: What Categories Reveal about the Mind. Chicago: University of Chicago Press.

Lakoff, G. \& Johnson, M. (1999). Philosophy in The Flesh. New York: Basic Books.

Landowski, E. (2004). Passions sans nom. Paris: Puf.

Langacker, R. (1991). Foundations of Cognitive Grammar. Stanford: Stanford University Press.

LeDoux, J. (1996). The Emotional Brain: The Mysterious Underpinnings of Emotional Life. New York: Simon \& Schuster.

Mahler, M. \& Furer, M. (1968). On Human Symbiosis and the Vicissitudes of Individuation. New York: International Universities Press.

Mahler, M., Pine, F. \& Bergman, A. (1975). The Psychological Birth of the Human Infant. New York: Basic Books.

Meltzoff, A.N. (1989). Foundations for developing a concept of self: The role of initation in relating self to other and the value of social mirroring, social modeling, and self practice in infancy. In Cicchetti, D. \& Beeghly, M. (eds.), The Self in Transitions: Infancy to Childhood. Chicago: University of Chicago Press.

Meltzoff, A.N. \& Moore M.K. (1977). Imitation of facial and manual gestures by human neonates. Science, 198: $75-78$.

Neisser, U. (ed.). (1993). The Perceived Self. New York: Cambridge University Press.

Nelson, K. (1996). Language in Cognitive Development : Emergence of the Mediated Mind. Cambridge: Cambridge University Press.

Noë, A. (2004). Action in Perception, Cambridge, MA: The MIT Press.

Noë, A. (2009). Out of Our Heads. Why You Are Not Your Brain, and Other Lessons from the Biology of Consciousness. New York: Hill \& Wang.

Paolucci, C. (2010). Strutturalismo e interpretazione. Milano: Bompiani.

Schneider, W. \& Bullock, M. (2009). Human Development from Early Childhood to Early Adulthood:Findings from a 20 Year Longitudinal Study. New York: Psychology Press.

Stern, D. (1985). The Interpersonal World of the Infant: A View from Psychoanalysis and Developmental Psychology. New York: Basic Books.

Trevarthen, C. (1979). Communication and cooperation in early infancy: A description of primary intersubjectivity. In Bullowa, M. (ed.), Before Speech. Cambridge: Cambridge University Press.

Trevarthen, C. (1989). Signs before speech. In Sebeok, T. \& Umiker Sebeok, J. (eds.), The Semiotic Web. Amsterdam: Mouton De Gruyter. 
Trevarthen, C. (1993). The self born in intersubjectivity: An infant communicating. In Neisser, U. (ed.), The Perceived Self: Ecological and Interpersonal Sources of Self-Knowledge (121-173). Cambridge: Cambridge University Press.

Trevarthen, C. (1998). The concept and foundations of infant intersubjectivity. In Bråten, S. (ed.), Intersubjective Communication and Emotion in Early Ontogeny (15-46). Cambridge: Cambridge University Press.

Trevarthen, C. \& Aitken, K.J. (2001). Infant intersubjectivity: Research, theory, and clinical applications. Journal of Child Psychology and Psychiatry, 4(1):3-48.

Trevarthen, C. \& Hubley, P. (1978). Secondary intersubjectivity: Confidence, confiding and acts of meaning in the first year. In Lock, A. (ed.), Action, Gesture, and Symbol: The Emergence of Language (183227). New York: Cambridge University Press.

Tronick, E., Als, H., Adamson, L., Wise, W. \& Brazelton, T.B. (1978). The Infant's response to entrapment between contradictory messages in face-to-face interaction. Journal of the American Academy of Child Psychiatry, 17: 95-106.

Tronick, E. (ed.). (1982). Social Interchange in Infancy: Affect, Cognition and Communication. Baltimore: University Park Press.

Violi, P. (2008). Beyond the body: Towards a full embodied semiosis. In Franck, R., Dirven, R., Ziemke, T. \& Bernárdez, E. (eds.), Body, Language and Mind. Volume 2: Sociocultural Situatedness (53-76), Berlin: Mouton de Gruyter.

Zahavi, D. (2001). Beyond empathy. Phenomenological approaches to intersubjectivity. Journal of Consciousness Studies, 8(5-7): 151-67. 